\title{
Terms of Use of Surface Active Substances (SAS) to Receive Quality Galvanic Coatings of Zinc
}

\author{
NADEZHDA ANDREEVNA VYSOTSKAYA, BALZHAN NURMANOVNA KABYLBEKOVA*, \\ ROSA SPABEKOVNA SPABEKOVA, KARIM TEMIROVICH KURBANBEKOV, GULMIRA \\ MENLIBAYEVA ADYRBEKOVA and SHAIZADA TURTAYEVNA KOSHKARBAYEVA
}

\author{
South Kazakhstan State University Named after M.Auezov, 160012, \\ Tauke Khan Avenue 5 Shymkent city, Kazakhstan. \\ *Correponding author E-mail: balzhan.kbn@bk.ru \\ http://dx.doi.org/10.13005/ojc/350413
}

(Received: May 04, 2019; Accepted: July 04, 2019)

\begin{abstract}
The use of metal galvanic zinc coatings for protection against corrosion reaches broad indicators due to their obvious advantages: simplicity of preparation, low cost, environmental friendliness, and a long period of resistance to the effects of an aggressive environment on the coating. Sulfuric electrolytes of galvanizing containing a complex of SAS used in combination with each other were investigated. Their effective influence on the protective properties and appearance of zinc coatings is shown. The qualitative and quantitative composition of zinc coatings on a JSM- $6_{490} \mathrm{LV}$ raster electron microscope with the systems of energy dispersive microanalysis of INSAEnergu and $\mathrm{HKL}$ - Basicc structural analysis with a useful magnification of 300,000 was investigated. Obtained non-porous, fine-crystalline, dense, bright galvanic zinc coatings from electrolytes with surfactants with good adhesion to the base, a comparison of their quality is given and conclusion is made.
\end{abstract}

\section{INTRODUCTION}

In world practice, zinc metal coatings obtained by electrolytic methods are widely used to protect products from corrosion. The nomenclature and volume of products protected from corrosion are very wide. This is explained by the chemical and physicochemical properties of electrolytic zinc coatings obtained using SAS ${ }^{1}$.

Existing modern technologies for producing protective zinc coatings provide for the choice of the technology that would satisfy all consumer requirements: increasing the service life of the coating, giving a marketable appearance to the coating, creating uniformity and resistance to peeling from the substrate (adhesion). The existing methods of thermal diffusion, hot, cold, gas-thermal, electrolytic galvanizing have their advantages and disadvantages: in the thermal diffusion method, the complexity and bulkiness of the equipment, in hot-dip galvanizing large zinc consumption and hydrogen embrittlement of the coating, in cold galvanizing the low durability of the coating and its sensitivity to

This is an Open Access article licensed under a Creative Commons license: Attribution 4.0 International (CC- BY). Published by Oriental Scientific Publishing Company @ 2018 
mechanical effects, gas-thermal coatings, porous. And only zinc coatings produced by an electrolytic method are less fragile, are sufficiently plastic, have good adhesion to the base, it is possible to control the coating thickness, lower zinc consumption (saving 50\%), high performance of the method, the ability to obtain brilliant zinc coatings with decorative character ${ }^{2}$.

As proof of the above, the authors ${ }^{3}$ investigated the electrolytic galvanizing of bearing rings of the electric wire of constant and alternating current. When using reverse current, a technological algorithm was developed for the galvanizing process (current density, duration, electrolyte temperature, anode consumption, coating thickness) of the bearing rings with improved coating structure and reduce its roughness, as well as increased galvanizing process performance.

The authors ${ }^{4,5,6}$ investigated the process of obtaining zinc coatings from sulfate electrolytes in the presence of SAS (polyethylene polyamine, 3-o-chlorovinylmethylene-5-phenyl-3n-furan-2none), using improved electrodeposition technology. Modernization of the sulfate electrolyte composition was carried out by preliminary phage sedimentation of zinc. It is established that the synthesized organic compounds SAS adsorbed on the surface of the electrode during its cathodic polarization, increasing the overvoltage of the crystallization process and creating conditions for the formation of the fine crystalline structure of the zinc coating.

Electrodeposition of zinc from an electrolyte solution containing zinc sulfate, sodium sulfate and potash alum as the main components, as well as various SAS, both separately and in a mixture, produces high-quality zinc coatings. By electron microscopy, the formation of light gray, matte, uniform coatings with good adhesion to the protected surface, on coatings, some gloss is acquired, the structure of the coating is significantly ground, its porosity decreases $7,8,9$.

The authors of ${ }^{10}$ have patented the method of electrolytic galvanizing of metal products on a processing line consisting of a reem. By the method of centrifuging and drying products, it becomes possible to initially transfer products from the first centrifuge to the second centrifuge. The centrifugation method helps to obtain high-quality zinc coatings.

The electrolyte of bright galvanizing containing in $\%$ is patented: zinc sulfate-10-20; sodium sulfate - 8-10; bone glue - 0.2-0.25; infusion of poplar fluff $-0.5-0.7$. Distilled water electrolyte by the authors brought to the specified volume. The process of electrodeposition is carried out at a temperature of $20-350^{\circ} \mathrm{C}$ and a high-quality zinc coating is obtained ${ }^{11}$. Studies by other authors ${ }^{12-20}$ are also devoted to the effect of various surfactants on the quality, brilliance and anti-corrosion properties of zinc coatings obtained from electrolytes of different composition and used in various industries.

\section{Purpose of the study}

The purpose of the research was to obtain high-quality coatings of zinc obtained from simple sulfate electrolytes containing SAS, both separately and in a mixture, under optimally selected modes of the electrodeposition process (temperature, current density, time).

\section{EXPERIMENTAL}

\section{MATERIALS AND METHODS}

Components for the preparation of electrolyte galvanizing used brand "hch": sodium sulfate, zinc sulfate, aluminum sulfate (or aluminum potassium alum). Soda was used to degrease electrodes, $0.1 \mathrm{~N}$ sulfuric acid solution was used to pick up electrode surfaces before the experiment, ethyl alcohol, SAS (sulfamic, citric acids, thiourea, hexamine) were used to dry the electrodes. Cathodes steel plates, anodes of electrolytic zinc.

Before applying the zinc coating, steel samples were machined with an emery paper of increasing numbers to remove roughness, degreased with soda or Eshka mixture, repeatedly washed with distilled water, dried with alcohol, weighed on an electronic scale. Through the surface of steel cathodes and a given current density (from 1 to $3.5 \mathrm{~A} / \mathrm{dm}^{2}$ ), the current strength was calculated to be fixed on the ammeter. The temperature was measured with a conventional thermometer. The structure of zinc coatings was studied with an electron microscope. According to the difference in the mass of deposited zinc and theoretically calculated by the Faraday law, the calculated output current (BT) was in \%. As the galvanizing process was carried out, the electrolyte was adjusted by injection of a small amount of sulfuric acid into the electrolyte at a temperature of $20^{\circ} \mathrm{C}$ to maintain the $\mathrm{pH}$ in the 3.5-4.5 range. The porosity of the zinc coating was determined using filter paper, moistened in solution (10 $\mathrm{g}$ of potassium ferrocyanide and 
$15 \mathrm{~g}$ of sodium chloride in 11 of water) by putting a paper on the sample surface. If there are pores in the zinc coating on paper, the blue dots of Turnbull blue should be printed. According to the number of printed pores per $1 \mathrm{~cm}^{2}$, the porosity was calculated in \%. Obtaining of zinc electroplating was carried out on the installation consisting of an electrolyzer, ammeter, rheostat, the constant current source with a total voltage of $220 \mathrm{~V}$.

Table 1: Quality of zinc coatings in electrolyte without SAS

\begin{tabular}{cccclc}
\hline $\mathrm{pH}$ & $\mathrm{I}_{\mathrm{k}}, \mathrm{A} / \mathrm{dm}^{2}$ & $\mathrm{t},{ }^{\circ} \mathrm{C}$ & $\mathrm{W}_{\mathrm{Zn}}, \%$ & $\begin{array}{l}\text { The appearance } \\
\text { of zinc coating }\end{array}$ & $\begin{array}{c}\text { Coating } \\
\text { thickness, } \mu \mathrm{m}\end{array}$ \\
\hline 3,5 & 1 & 20 & 91 & $\begin{array}{l}\text { Dark gray, coarse- } \\
\text { grained, porous }\end{array}$ & 1,82 \\
3,5 & 1,5 & 20 & 91,6 & $\begin{array}{l}\text { Dark gray, coarse } \\
\text { crystalline, porous }\end{array}$ & 1,74 \\
3,5 & 2 & 20 & 91,2 & $\begin{array}{l}\text { Dark gray, loose, } \\
\text { porous }\end{array}$ & 1,70 \\
3,5 & 2,5 & 20 & 92,8 & $\begin{array}{l}\text { Dark, with burns } \\
\text { Dark, exfoliate }\end{array}$ & 1,42 \\
3,5 & 3 & 20 & 90,8 & 1,21 \\
3,5 & 3,5 & 20 & 91,4 & Dark, burnt & 1,34 \\
\hline
\end{tabular}

\section{RESULTS AND DISCUSSION}

Table 1 shows the appearance of zinc coatings obtained from an electrolyte without SAS, W.

The appearance of zinc coatings does not meet the required quality: coatings are coarsecrystalline, dark and gray, at higher current densities exfoliate, with burns along the edges. The share of the volume of blue points of Turnbull blue in the total volume of the porous coating is rather high. Such a structure of zinc coating does not contribute to the effective protection of the product from corrosion, penetration of corrosive medium to the surface of the product through the pores and the flow of corrosion through the electrochemical mechanism with the destruction of the product under a protective coating is possible. The current output is low (91\%).

Table 2 shows the appearance of zinc coatings obtained from an electrolyte with the addition of a mixture of citric acid and hexamine, $\mathrm{W}$.

The table shows that the presence of a SAS mixture in the electrolyte has a positive effect on the quality of zinc coatings, coatings are lighter, more dense and crystalline, blue dots of turbulence blue are not imprinted on filter paper, gloss appears at a current density of $2.5 \mathrm{~A} / \mathrm{dm}^{2}$, however, with increased current densities on the coating, scorching occurs. Current output in electrolyte with SAS is higher $(98 \%)$, in comparison with electrolyte without SAS. Zinc coatings obtained at current densities of 2-2.5A/ $\mathrm{dm}^{2}$, can meet the requirements for the protection of products against corrosion.

Table 3: Quality of zinc coatings in electrolyte with SAS (hexamine + thiourea), W

\begin{tabular}{cccclc}
\hline $\mathrm{pH}$ & $\mathrm{I}_{\mathrm{k}}, \mathrm{A} / \mathrm{dm}^{2}$ & $\mathrm{t},{ }^{\circ} \mathrm{C}$ & $\mathrm{W}_{\mathrm{Zn}}, \%$ & $\begin{array}{l}\text { The appearance } \\
\text { of zinc coating }\end{array}$ & $\begin{array}{c}\text { Coating } \\
\text { thickness, } \mu \mathrm{m}\end{array}$ \\
\hline 3,6 & 1 & 20 & 95,2 & Light gray, loose & 2,04 \\
3,6 & 1,5 & 20 & 95,7 & Light gray & 2,02 \\
3,5 & 2 & 20 & 96,4 & Light, tight & 2,21 \\
3,5 & 2,5 & 20 & 97,2 & Light, dense, porous & 2,12 \\
3,6 & 3 & 20 & 95,1 & Gray, exfoliate & 2,12 \\
3,6 & 3,5 & 20 & 93,2 & Gray, crumbling & 2,14 \\
\hline
\end{tabular}

Table 3 shows the appearance of zinc coatings obtained from an electrolyte with the addition of a mixture of hexamine and thiourea, $\mathrm{W}$.

Table 2: Quality of zinc coatings in electrolyte with SAS (citric acid + hexamine), W

\begin{tabular}{|c|c|c|c|c|c|}
\hline $\mathrm{pH}$ & $\mathrm{I}_{\mathrm{k}}, \mathrm{A} / \mathrm{dm}^{2}$ & $t,{ }^{\circ} \mathrm{C}$ & $W_{z n}, \%$ & $\begin{array}{l}\text { The appearance } \\
\text { of zinc coating }\end{array}$ & $\begin{array}{l}\text { Coating } \\
\text { thickness, } \mu \mathrm{m}\end{array}$ \\
\hline 3,5 & 1 & 20 & 97,4 & Light gray, tight & 2,13 \\
\hline 3,6 & 1,5 & 20 & 96,8 & $\begin{array}{l}\text { Light, dense, stained } \\
\text { non-porous }\end{array}$ & 2,02 \\
\hline 3,7 & 2 & 20 & 99,2 & $\begin{array}{l}\text { Light, fine crystalline, } \\
\text { non-porous }\end{array}$ & 2,25 \\
\hline 3,7 & 2,5 & 20 & 98,9 & $\begin{array}{l}\text { Light, brilliant, dense, } \\
\text { non-porous }\end{array}$ & 2,12 \\
\hline 3,7 & 3 & 20 & 95,9 & Light with burn & 2,12 \\
\hline 3,7 & 3,5 & 20 & 94,2 & Light, exfoliate & 2,08 \\
\hline
\end{tabular}

The table shows that the presence of SAS in the electrolyte affects the quality of zinc coatings, coatings are light gray, but not dense, at a current density of $2.5 \mathrm{~A} / \mathrm{dm}^{2}$, denser, non-porous, however, at high current densities, zinc coatings darken, exfoliate and fall off. The current efficiency in the electrolyte is higher compared to electrolyte without SAS.

Comparing the results of Tables 1-3, it is safe to say that effective SAS are: a mixture of citric acid and hexamine, a mixture of hexamine and thiourea. Zinc coatings are light, crystalline, nonporous, with shine. However, the current density limit for obtaining high-quality coatings is limited to $2.5 \mathrm{~A} /$ $\mathrm{dm}^{2}$. Higher current densities make it impossible to obtain high-quality zinc coatings.

Figures 1, 2, 3 show zinc coatings obtained from an electrolyte without SAS and with additives 
at a current density of $2 \mathrm{~A} \mathrm{dm^{2 }}$, recorded with an electron microscope.
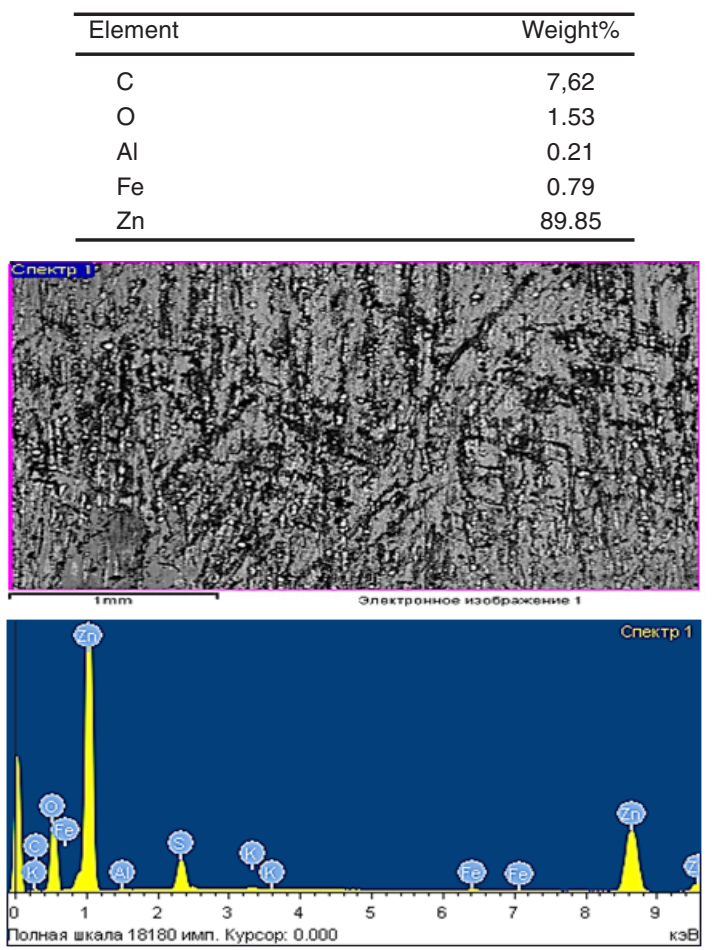

Fig. 1. Zinc coating and its elemental composition in electrolyte galvanizing without SAS

From the above image, the crystalline structure of the zinc coating is seen. The coating is dark, visible porosity, roughness. This coating may not contribute to the effective protection of the product against corrosion.

The second image shows the structure of a zinc coating obtained from an electrolyte with the addition of SAS citric acid and hexamine.

From the figure, a significant lightening of the zinc coating is clearly visible, the coating is denser, no pores are observed. It can be assumed that such a coating will reliably protect the product from corrosion.

In the figure we see a light coating, fine crystalline and non-porous. Comparing the quality indicators of zinc coatings recorded with an electron microscope in Fig. 1,2,3, we can say with confidence that the zinc coatings we obtained, with selected surfactants, are a non-porous, dense, compositionally appropriate zinc coating that can withstand corrosive effects. Based on these tables and figures, conclusions can be drawn about the effective effect of the SAS mixture on the quality of zinc coatings obtained from acidic electrolytes.

\begin{tabular}{cc}
\hline Element & Weight\% \\
\hline $\mathrm{C}$ & 7.08 \\
$\mathrm{O}$ & 1.62 \\
$\mathrm{Al}$ & 0.20 \\
$\mathrm{Fe}$ & 0.08 \\
$\mathrm{Zn}$ & 91.40 \\
\hline
\end{tabular}
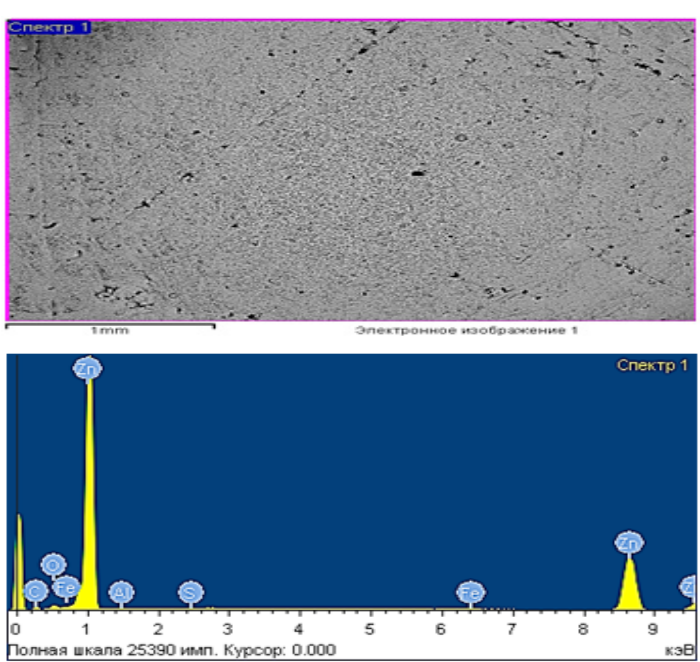

Fig. 2. Zinc coating and its elemental composition in the electrolyte with the addition of citric acid and hexamine

\begin{tabular}{cc}
\hline Element & Weight\% \\
\hline $\mathrm{C}$ & 6.93 \\
$\mathrm{O}$ & 1.71 \\
$\mathrm{Al}$ & 0.18 \\
$\mathrm{~S}$ & 1.0 \\
$\mathrm{Fe}$ & 0.04 \\
$\mathrm{Zn}$ & 90.14 \\
\hline
\end{tabular}
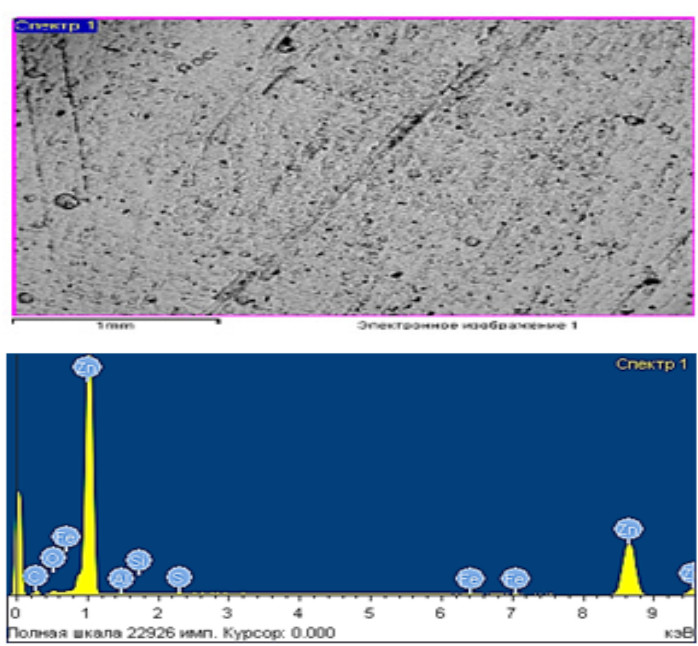

Fig. 3. Zinc coating and it's elemental composition of the electrolyte with the hexamine and thiourea additives 
Based on the position of the adsorption theory of electrocrystallization of metals, it can be assumed that the combined action of SAS under the conditions of zinc electroplating contributes to shielding the surface of the protected product and creates conditions for obtaining a fine-crystalline, dense, non-porous zinc coating. In the case of a mixture of thiourea and urotropine, sulfide sulfur seems to have an inhibiting effect, and in the case of urotropine and citric acid, bound nitrogen.

Comparing the results obtained by us on the quality of zinc coatings with the results given in the analytical review (introduction), we can say with confidence that our zinc coatings are not inferior in quality to those obtained by other authors. They are distinguished by the simplicity of the composition of the electrolyte, the mode of the process and the low cost of surfactants.

\section{CONCLUSION}

1. The process of electrolytic production of zinc coatings from acid galvanizing electrolyte without a SAS and with a mixture of SAS was investigated, the mode of the process, the quality of zinc coatings was determined. The composition of the electrolyte g/l: Zinc sulphate- 215 , aluminum sulphate-30, sodium sulphate-100, SAS-0.5-2; current density $1-3.5 \mathrm{~A} / \mathrm{dm}^{2}$, temperature $-20^{\circ} \mathrm{C}$.

2. An examination of the quality of zinc coatings: appearance control(color, shade, roughness, burn, porosity, gloss), calculated thickness of zinc coatings, determined their porosity, calculated W.

3. An energy dispersive microanalysis of the composition of zinc coatings was carried out.

4. Conditions for obtaining high-quality zinc coatings to protect products from corrosion were recommended.

\section{ACKNOWLEDGMENT}

The work was supported on the state budget direction of the South-Kazakhstan State University named after M.Auezov.

\section{Conflicts of Interest}

The authors declare no conflict of interest

\section{REFERENCES}

1. Hamburg, Yu.D.; Galvanic coatings: a Handbook. -Moscow: Tekhnosfera, (Russian)., 2006, 216.

2. Astalyuhina A.S., Pikalov E.S. Successes of Modern Natural Science, (Russian)., 2015, 11-1, 11-14.

3. Muraviev D.V., Maksimov V.V. Proceedings of the OSU. Omsk, (Russian)., 2012, 27-31.

4. Minin I.V., Soloveva N.D., Chadina V.V., Lazarev I.V., Nanotechnologies: science and production, (Russian)., 2011, 3(12), 61.

5. Minin I.V., Soloveva N.D., News SPSUT, (Russian)., 2013, 1, 57-62.

6. Minin I.V. Abstract: Candidate of Technical Science. -Saratov, (Russian)., 2013, 19.

7. Vysotskaya N.A., Kabylbekova B.N., Isabaeva K.E., Kurbanbekov K.T., Bekzhigitova K.A. Proceedings of the XXXII International Scientific and Practical Conference "Science in the Modern World".-Moscow., (Russian)., 2018, 129-133.
8. Vysotskaya N.A., Kabylbekova B.N., Isabaeva K.E., Bitanova G.A. Auezov Readings -16: The Fourth Industrial Revolution: New Opportunities for the Modernization of Kazakhstan in the Field of Science, Education, Culture: Abstracts of Doctr. International scientific and practical conf. Shymkent., (Russian)., 2018, 6, 89-92.

9. Kabylbekova B.N., Bekzhigitova K.A., Tastanbekov B.I., Karynbaeva M.P. Auezov readings -16 : The fourth industrial revolution: new opportunities for the modernization of Kazakhstan in the field of science, education, culture: abstracts of the reports International scientific and practical conf. Shymkent, (Russian)., 2018, 6, 147-150.

10. Vladimirova V.F.; Katkova E.A.; Electrolyte brilliant galvanizing, Russian Federation 2343232, Publ., 2009, 10, 01.

11. Vladimirova V.F.; Kazieva L.A.; Electrolyte brilliant galvanizing, Russian Federation 2350695 publ., 2009, 27, 03. 
12. Vysotskaya N.A., KabylbekovaB.N., Spabekova R., Bekzhigitova KA, Kurbyuanbekov K.T., Ormanova G.K., Lukin E.G. Protective zinc coatings from acid electrolyte galvanizing // News of NARK., 2019, 3(435),122-126.

13. MuralidharaH.B, NaikArthobaY. Nanotechnology study of zinc coatings //Bull.mater/ sci., 2008, 31(4), 585-591.

14. Kovyazina, I.I., Naidenova, Yu.S. The influence of surfactants on the electrodeposition of zinc from sulfate electrolyte//Collection of materials Vseros. Scientific and Technical Conf. - Kirov., 2006, 77-81.

15. Pat. 200611438802 of the Russian Federation. The method of electrolytic galvanizing products/Dorodko VV, Solovyov GS; publ., . 2007, 27, 05.

16. Hamunella V., Medvedev G.I., Makrushin N.A.
Electrodeposition of brilliant zinc coatings from sulphate electrolyte//Advances in Chemistry and Chemical Technology., 2006. 9, $90-92$.

17. Wan Renrong, Chen Yong - Yan. The method of electrodeposition of $\mathrm{Zn}$ at high speed in the sulphate bath and the properties of the coating, Kit., 2007, 65-66.

18. Krisha M.M.,Assaf F.H., Toghan A.A. Electrodeposition of $\mathrm{Zn}-\mathrm{Ni}$ alloys from sulphate bath // J. Solid State Electrochem., 2007, 11(2), $244-252$.

19. Pat. 102005002706 United States. The method of coating / DangerE., PohIM.; publ. 07/20/2006.

20. Borisov N.B. Zinc in the market of anticorrosion coatings., 2008, 2, 10-12. 